\title{
PRELIMINARY OBSERVATIONS OF ACOUSTIC EMISSIONS PREGEDING AVALANCHES
}

\author{
By Righard A. Sommerfeld \\ (U.S. Department of Agriculture Forest Service, Rocky Mountain Forest and \\ Range Experiment Station, Fort Collins, Colorado 8052 I, U.S.A.)
}

\begin{abstract}
Spontaneous emissions of noise were monitored in a snowpack on an avalanche track using three geophones. $30 \mathrm{~Hz}$ noise was recorded on magnetic tape for the whole avalanche season and $3 \mathrm{~Hz}$ noise for a short period of time. Periods before and during avalanches were associated with high noise, while periods of known stability were associated with low noise.

RÉsumé. Signaux acoustiques précédant les avalanches. A l'aide de trois géophones, on a enregistré les émissions spontanées de bruits dans la neige d'un couloir d'avalanche. Un bruit de $30 \mathrm{~Hz}$ fut enregistré sur bande magnétique pour l'ensemble de la saison des avalanches et un bruit de $3 \mathrm{~Hz}$ pour une courte période de temps. Les périodes où se sont produites des avalanches étaient associées à des bruits forts tandis que celles de stabilité connue étaient associées à des bruits faibles.

Zusammenfassung. Schallemission vor Lawinenabgängen. Mit Hilfe von drei Geophonen wurden spontane Emissionen von Geräusch in einer Schneedecke auf einer Lawinenbahn festgestellt. Während der gesamten lawinengefährdeten Jahreszeit wurde Geräusch von $30 \mathrm{~Hz}$ auf Magnetband registriert, Geräusch von $3 \mathrm{~Hz}$ dagegen nur für eine kurze Zeitspanne. Perioden mit Lawinenabgängen waren durch hohe Geräusche gekennzeichnet, Perioden mit stabilen Verhältnissen dagegen durch tiefe Geräusche.
\end{abstract}

\section{INTRODUGTION}

Snow slopes vary in stability. At one time, it may be impossible to initiate slab avalanches, while at another time, they occur spontaneously. The evaluation and prediction of these changes in slope stability are central problems in avalanche research. It is possible that snow slopes exhibit some phenomena which indicate the development of instability. One possible phenomenon is spontaneous acoustic emissions generated by the snow as it approaches instability or failure (St. Lawrence and Bradley, 1973). I report here observations of spontaneous emissions of low-frequency noise $(\mathrm{I}-30 \mathrm{~Hz})$ from snow-packs prior to avalanches.

\section{INSTRUMENTATION}

Three geophones (Geo Space HS-I, $28 \mathrm{~Hz}$ )* were used to detect the acoustic signals. They were mounted on heavy metal grills, about $30 \mathrm{~cm}$ square. A pre-amplifier, with an input impedance of $\mathrm{I}$ kohm and a gain of $40 \mathrm{~dB}$ over a frequency range of $\mathrm{DC}$ to $\mathrm{ro} \mathrm{kHz}$, was connected to each geophone. The frequency response of the geophone damped by i $\mathrm{k} \Omega$ can be described as a resonance peak of $9 \mathrm{~dB}$ at $28 \mathrm{~Hz}$ that rolls off at $20 \mathrm{~dB}$ per octave at lower frequencies and decays to a flat response above I $25 \mathrm{~Hz}$. The signals were transmitted on shielded cable $20 \mathrm{~m}$ to a hut, where they were recorded on a Geotech model 19429 at 0.06 i.p.s. using direct-record electronics. The frequency response was $0.5-125 \mathrm{~Hz}$ at the $-3 \mathrm{~dB}$ points.

Initial examination of the voltage distributions showed frequency peaks at approximately 3, 30, 6o and $120 \mathrm{~Hz}$. The two higher-frequency peaks were interpreted to be power-line noise, based on visual examination of the analog signals and the fact that their amplitudes were fairly constant. The peak at $3 \mathrm{~Hz}$ was weak and the peak at $30 \mathrm{~Hz}$ coincides with the resonant frequency of the geophones.

* Trade names and company names are used for the benefit of the reader and do not imply endorsement or preferential treatment by the U.S. Department of Agriculture. 
The tapes were played back on a Honeywell 7600 at 30 i.p.s., giving a time compression of $500: \mathrm{r}$. The output from the tape recorder went to the input of a Princeton Applied Research model i io filter amplifier set to a resonance peak of $15 \mathrm{kHz}(30 \mathrm{~Hz}$ real time) a $Q$ of $\mathrm{ro}$ and a gain of 2 ooo. The output of the filter amplifier went to the input of a Hewlett Packard model $5245 \mathrm{~L}$ frequency counter. The counter was set to count pulses above a trigger level for I $\mathrm{s}$ intervals, or $500 \mathrm{~s}$ real time. In each case the trigger level was set to give a count rate of about 30 during low-noise periods and this resulted in count rates of about 300 during high-noise periods. The trigger levels ranged between 0.15 and $0.25 \mathrm{~V}$. The digital output of the counter was converted to an analog signal by a Hewlett Packard $562 \mathrm{~A}$ printer and recorded on a Hewlett Packard model $7044 \mathrm{~A} x-y$ recorder.

The geophones were installed in one part of the Cliffs Avalanche path at Berthoud Pass, Colorado, U.S.A., on 22 November 1974 at about $20.00 \mathrm{~h}$ (all times given in this paper are Universal Time: Zone $\mathrm{T}$ time plus $7 \mathrm{~h}$ ). They were placed on about $0.7 \mathrm{~m}$ of snow and spaced about $2 \mathrm{~m}$ apart along a contour as close as possible to the expected crown. Recordings were made continuously from 22 November 1974 to 30 April 1975.

\section{Results}

I should like to emphasize here the preliminary nature of this study. The basic signal amplitudes and frequencies which might be present were not known. Examination of the tapes shows the possibility of signals over a wide range of frequencies but many ambiguities were introduced by tape-recorder noise.

It was only where extra sensitivity was available from the geophone resonance that signals could be reliably detected above the tape-recorder noise level. The only exception to this is the one case where the signal was filtered at $3 \mathrm{~Hz}$ and heavily amplified before recording.

The marginal character of the recordings required very careful adjustment of the trigger level and counting rate to separate the signal from the system noise. The plots are the best presentation possible in each case. The information exists only in the change of signal above the background noise in each case and quantitative comparisons between plots would have no meaning.

The data tapes for the entire winter were analyzed by counting the number of noise pulses per $500 \mathrm{~s}$ above an arbitrary trigger level at $30 \mathrm{~Hz}$. The trigger levels ranged between 0 . I 5 and $0.25 \mathrm{~V}$. The periods leading up to the three avalanches which occurred in the experimental area were analyzed with particular care. Plots of relative counts per 500 s for representative periods are given in the five illustrations.

\section{December avalanche}

Figure IA-C shows the records from the three geophones for 18-22 December. The first, short noise peak is due to equipment maintenance. Starting about 12.00 h, I9 December, the count increased abruptly and then tapered off. By $14.00 \mathrm{~h}, 20$ December, the noise was close to, but perhaps slightly above, background. At $20.30 \mathrm{~h}, \mathrm{a} 0.7 \mathrm{~m}$ thick slide was released when we attempted to enter the area to install some equipment. The noise appears to have begun to increase about $3 \mathrm{~h}$ prior to the release, although some of the noise just prior to release was caused by our movements in the area.

The high noise level which starts abruptly at about I6.30 h, 2 I December, and ends abruptly at $23.30 \mathrm{~h}$ was generated by a chair lift in operation approximately $300 \mathrm{~m}$ from the geophones. While the chair lift is operating, its noise obscures any other signal. However, it is normally in operation only $6-7 \mathrm{~h}$ during the day, and noise signals at other times are easily distinguished. 

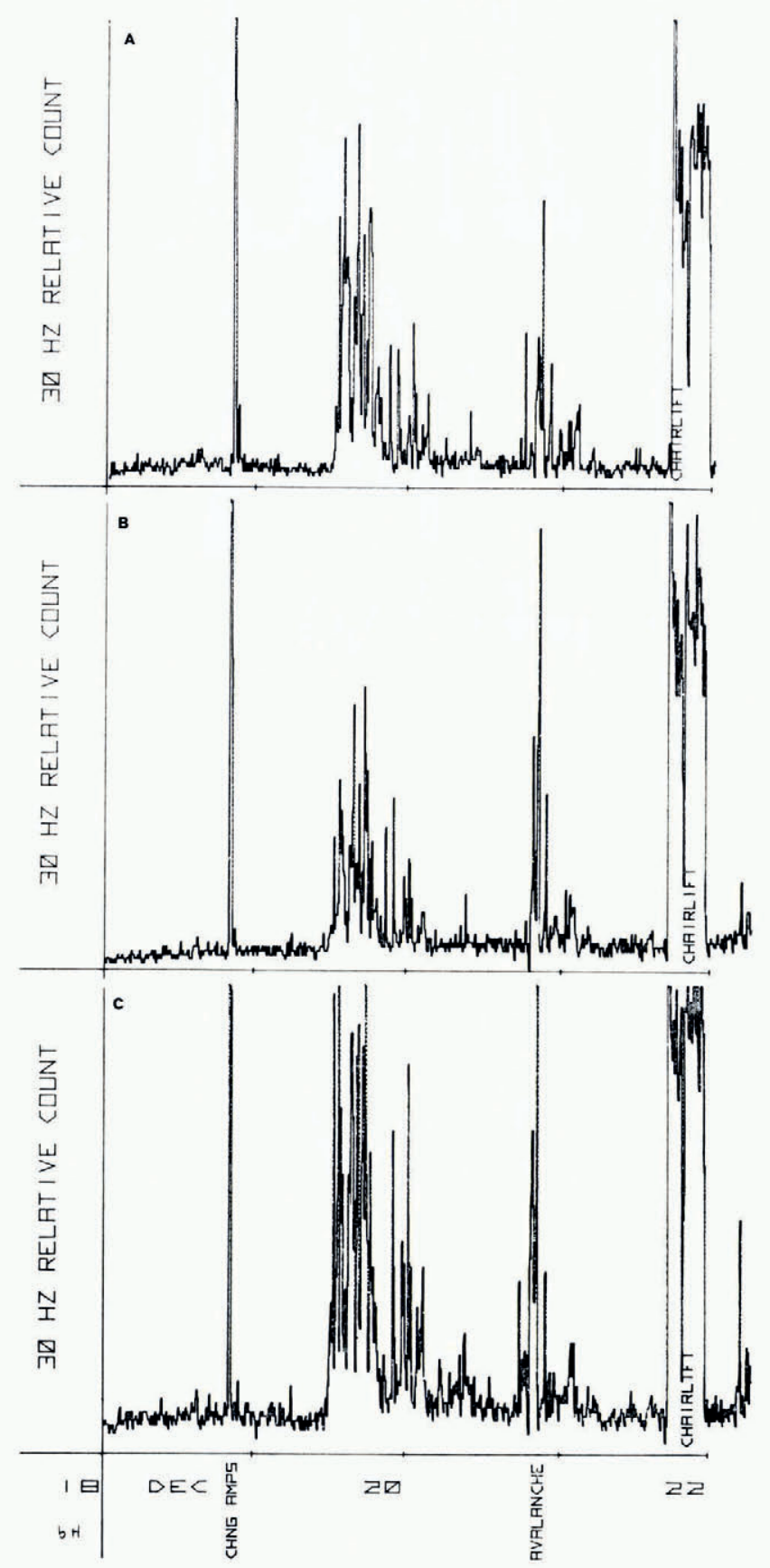

Fig. I. 20 December avalanche. $3^{\circ} \mathrm{Hz}$ counts from geophones $A, B$ and $C$. 


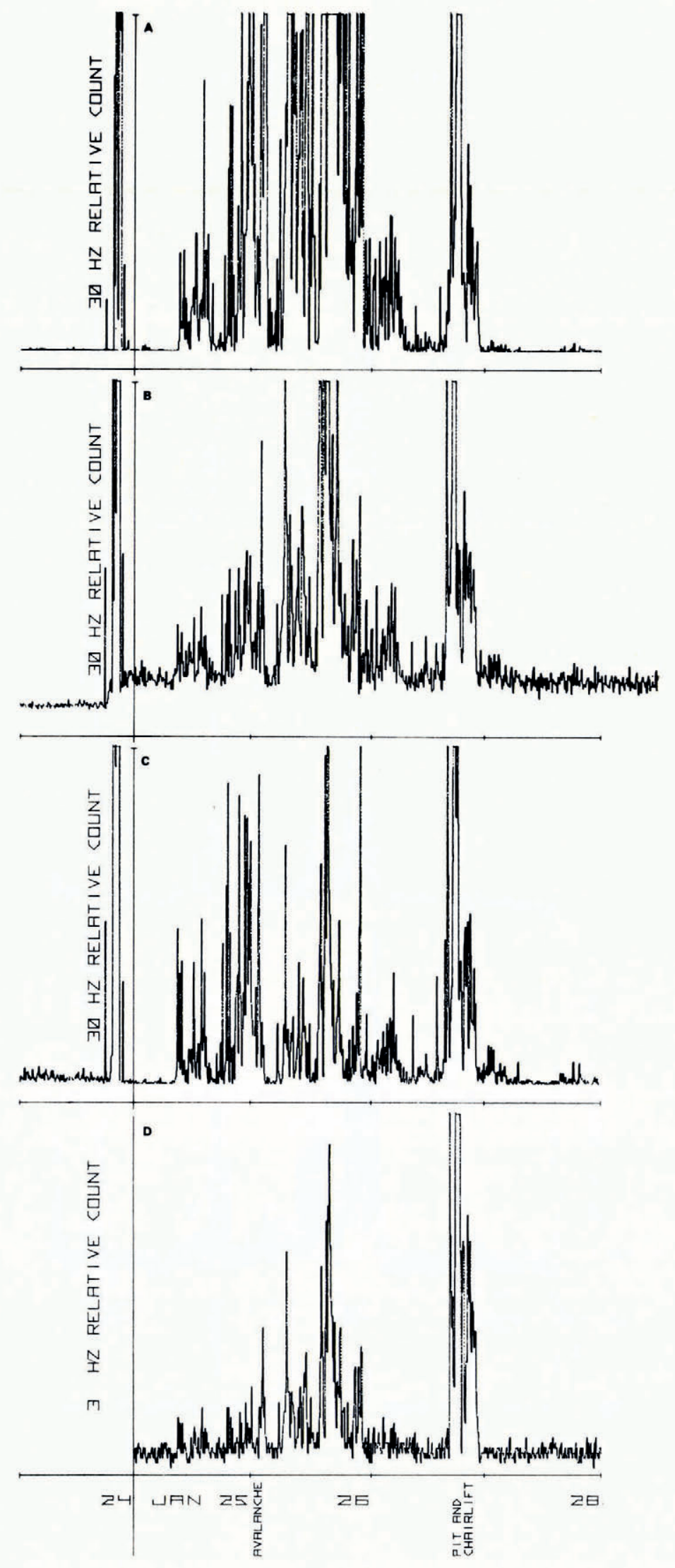




\section{Fanuary avalanche}

At about $18.00 \mathrm{~h}, 23$ January, the experimental area was known to be stable, since we installed a set of deformation gages without triggering a slide. The noise level remained low (Fig. 2) until $07.00 \mathrm{~h}, 24$ January, at which time the counts slowly began to increase. At $02.00 \mathrm{~h}, 25 \mathrm{January}$, a major slide released naturally to a depth of $2 \mathrm{~m}$. The counts dropped to the background level for about $2 \mathrm{~h}$, then increased and exhibited a 6 or $7 \mathrm{~h}$ periodicity. At about $06.00 \mathrm{~h}, 26$ January, the counts dropped to a low background level and remained there. During the high-noise period a storm was loading the presumably unstable track at a high rate. At $22.00 \mathrm{~h}, 25 \mathrm{January}$, the crown originally left by the avalanche was observed to be completely buried. At 18.00 h, 26 January, a pit was dug at the buried crown. Evidently the slope was stable at this time, since a slide was not released. The noise counts were relatively low except for those generated by the pit digging and the operation of the chair lift.

During this period the signal from geophone $\mathrm{B}$ was also filtered at $3 \mathrm{~Hz}$, amplified with an additional gain of $80 \mathrm{~dB}$ to overcome the low sensitivity at $3 \mathrm{~Hz}$, and recorded on a separate tape channel. The counts from this recording (Fig. 2D) show essentially the same details as the $30 \mathrm{~Hz}$ records. The only difference which may be significant is that the ratio of "snow noise" to chair-lift noise is higher at $30 \mathrm{~Hz}$ than at $3 \mathrm{~Hz}$.

\section{April avalanche}

The signals from the three geophones at this time were not as consistent as those for the other avalanche periods (Fig. 3). Geophones A and B give essentially the same information but geophone $\mathrm{C}$ appeared to be extra sensitive. Signals started earlier and continued longer, and the signal-to-background ratio was higher than for the other two. There is reason to believe geophone $\mathrm{C}$ was closer to the area of slide initiation than the other two. In any case, the natural avalanche which occurred about $12.00 \mathrm{~h}$, 99 April, is well correlated with the noise counts.

\section{I6 February period of stability}

I4-I 8 February was a period of relatively low noise except for the chair lift. At 2 I.oo h, I5 February, the ski area received extensive explosive control with no avalanches. While the experimental area was not controlled, there is generally a correlation between its stability and that of the other slide paths in the ski area (Fig. 4).

\section{April period of stability}

From 7 to i I April, the noise counts were very low. On 9 April, i8.oo h, a charge was detonated in the experimental area but no avalanche resulted. The charge was thrown in from the side; we did not walk within approximately $20 \mathrm{~m}$ of the geophones (Fig. 5).

\section{Discussion}

The examples shown here were typical of the season's record. There were other periods of low and high noise when there was no independent information on the stability of the snow pack. When information was available, however, there was a clear correlation between the $30 \mathrm{~Hz}$ noise levels detected by the three geophones and snow-slope stability in the experimental

Fig. 2 (opposite). 25 January avalanche. $30 \mathrm{~Hz}$ counts from geophones $\mathrm{A}, \mathrm{B}$ and $\mathrm{C} ; \mathrm{D}, 3 \mathrm{~Hz}$ counts from geophone $\mathrm{B}$. 


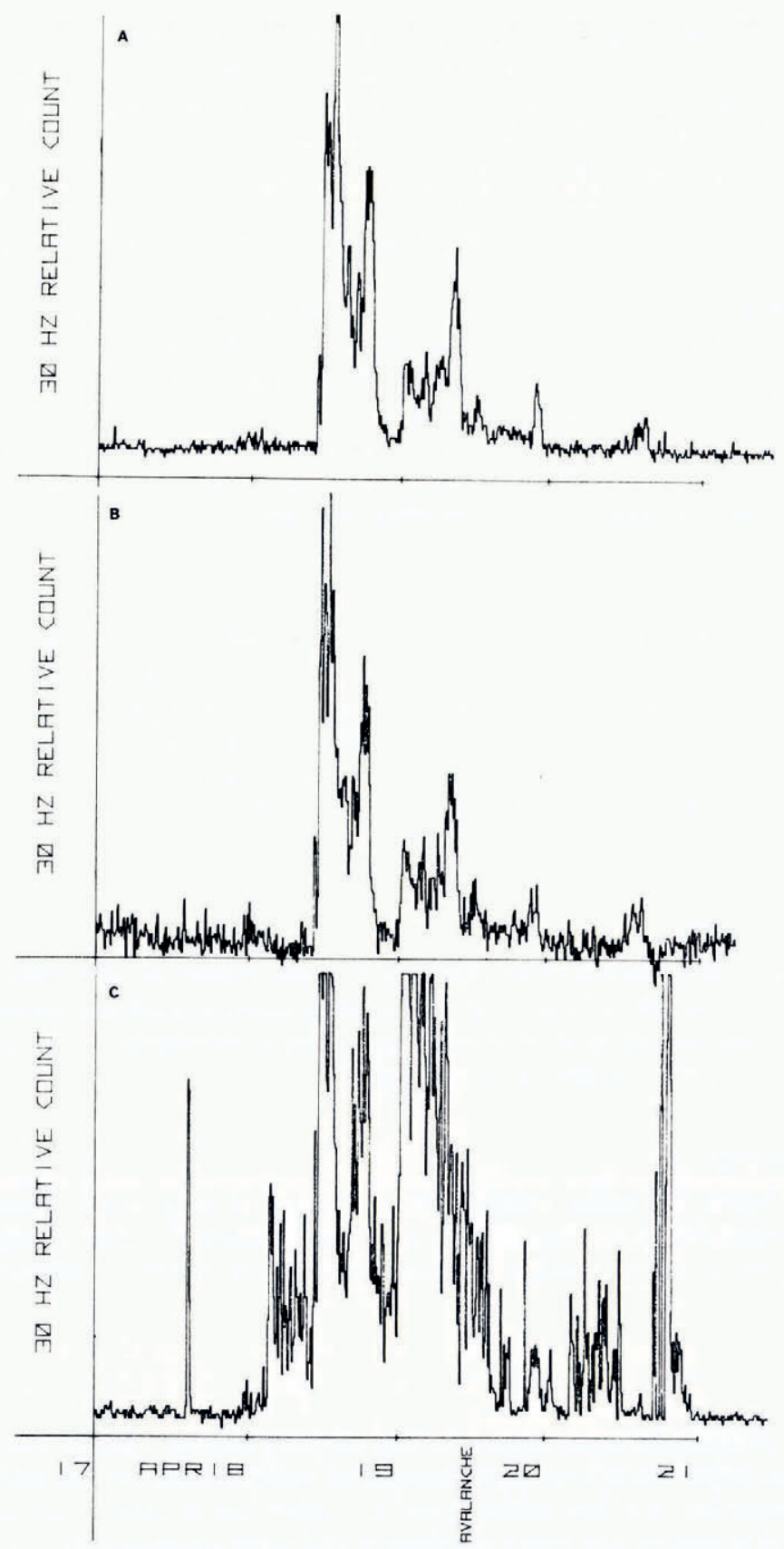

Fig. 3. 19 April avalanche. $3^{\circ} \mathrm{Hz}$ counts from geophones $A, B$ and $C$. 


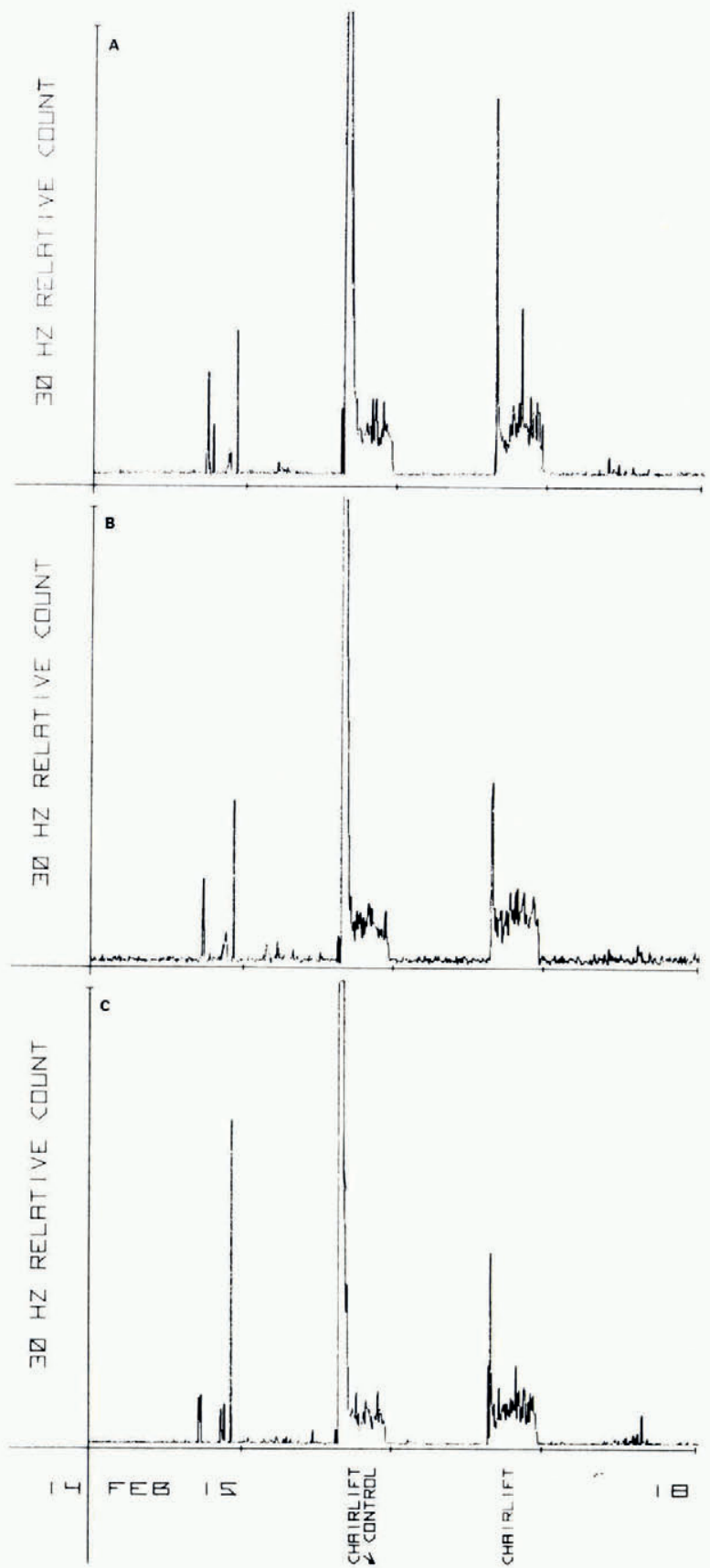

Fig. 4. 16 February period of stability. $3^{\circ} \mathrm{Hz}$ counts from geophones $\mathrm{A}, \mathrm{B}$ and $\mathrm{C}$. 


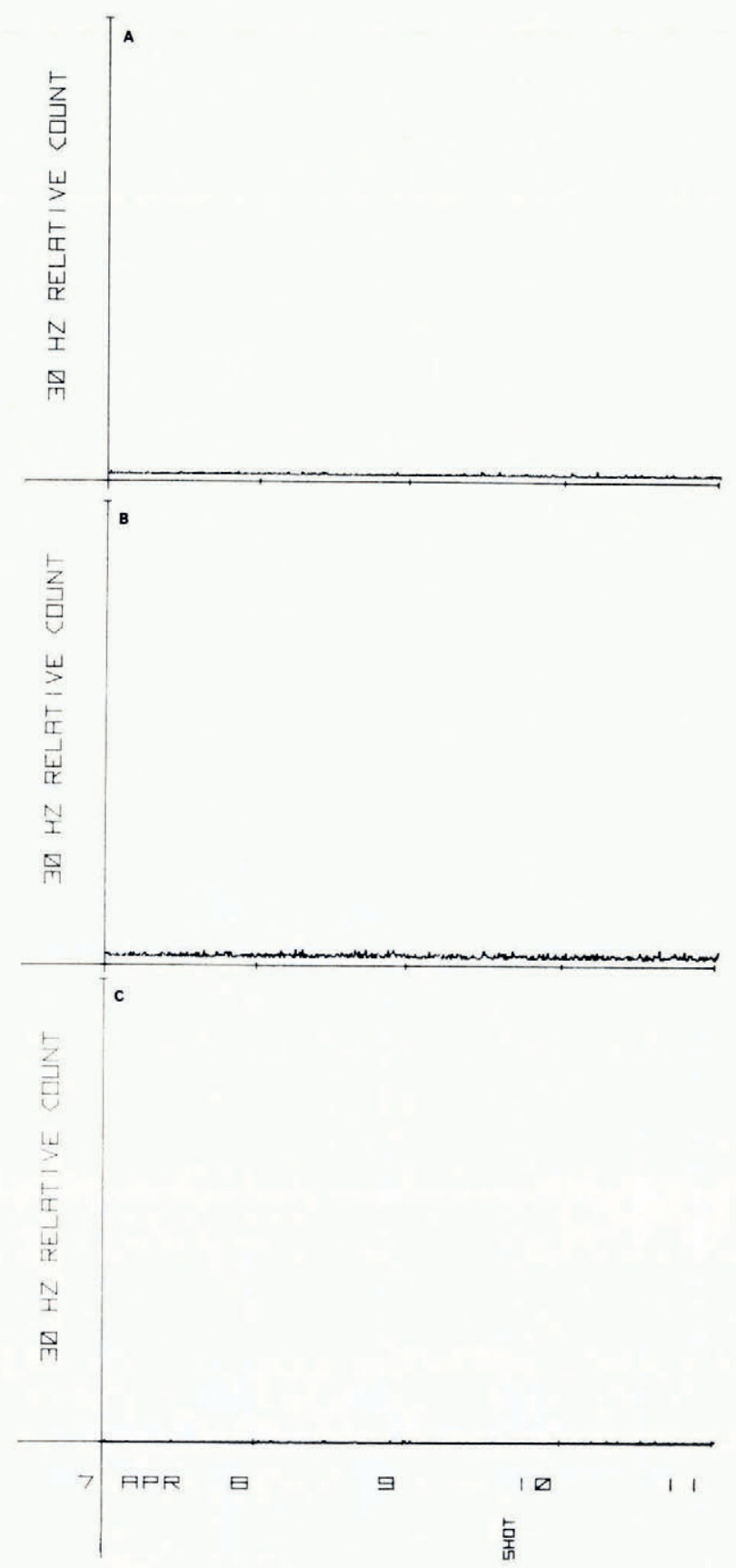

Fig. 5. 9 April period of stability. $30 \mathrm{~Hz}$ counts from geophones $A, B$ and $C$. 
area. The three avalanches in the experimental area occurred during or immediately following periods of high noise. The artificially released avalanche on 20 December closely followed a period of high noise and was probably preceded by a short period of increasing noise. In each case, the increase in noise over the background was large enough so that a definite warning of at least $\mathrm{I}_{5} \mathrm{~h}$ was available before each avalanche.

On the other hand, there is no threshold level of noise above which avalanching is inevitable. In fact, the natural avalanche on 25 January was preceded by lower noise levels than the artificial release of 20 December. Furthermore, the relative sensitivities of the different geophones appeared to change with time, which might be expected. The snow-pack was experiencing active metamorphism during the entire period, and undoubtedly the characteristics of the snow-geophone system changed continually. Note the change in background level of geophone B due to our work in the area on 24 January (Fig. $2 \mathrm{~B}$ ). We may have walked directly over this geophone, changing the snow characteristics.

The careful placement of the geophones probably aided in increasing the signal-to-noise ratio. They were mounted parallel to the fall line, in close proximity to the area of expected disturbance. For the first avalanche, the geophones were on the sliding surface and were partly exposed by the avalanche. In the second avalanche, they were less than a meter up-slope from the crown and probably very near the sliding surface. The situation for the last slide was not determined. None of the avalanches ran to the ground, nor did they pull out the geophones.

The vertical placement of the geophones on the body of the snow likely contributed to the strength of the signals also. Recently proposed mechanisms for avalanche initiation (Perla, [1975]) postulate a weakening of the shear support at or just below the sliding layer. Such a weakening could degrade the transmission of sound and a sensor placed too deep in the pack might lose sensitivity.

The low frequency of the signals probably also increased the signal-to-noise ratio. The attenuation characteristics of snow are not well known but it is known that low frequencies are transmitted much better than high frequencies (Lang, I976). However, the limited data presented here suggest that $30 \mathrm{~Hz}$ is a more sensitive frequency than $3 \mathrm{~Hz}$. A comparison of the two frequencies from the same geophone (Fig. $2 \mathrm{~B}$ and D) shows a lower signal relative to the chair-lift noise at $3 \mathrm{~Hz}$ than at $30 \mathrm{~Hz}$. Either the chair lift put out more noise at $3 \mathrm{~Hz}$ or the snow put out less.

The origin of the low-frequency noise has not been determined. The frequencies generated by the fracturing of the ice network are of the order of $10^{5} \mathrm{~Hz}$ (St. Lawrence and Bradley, 1973) and it is unlikely that they are involved in the lower-frequency signals. It may be that macroscopic rupture generates these lower frequencies. The initiation of hard-slab avalanches and the collapse of depth hoar commonly produce sounds at the lower-frequency limit of human perception. Perhaps a similar but lower-level phenomenon was detected here.

An examination of the weather records during the season shows no obvious correlation between the signals and wind speed, but I did observe a correlation with precipitation. In general, however, precipitation begins before the noise level starts to increase and the higher noise persists after the precipitation ends. This type of behavior would be expected if the noise level is directly correlated with instability.

While the results presented here are extremely encouraging, they do not, as yet, resolve the problem of the development of a reliable short-term stability predictor. Not enough events have been recorded to establish reliability. Also, the marginal character of the records, as previously discussed, leaves a basic question unanswered. To be used operationally, the signals would have to be large enough, compared to the background, so that the trigger level could remain the same over long periods of time. Higher amplification of the signals before recording should resolve the problem. 


\section{REFERENGES}

Lang, T. E. 1976. Measurements of acoustic properties of hard-pack snow. Fournal of Glaciology, Vol. 17, No. 76 , p. 269-76.

Perla, R. I. [1975.] Stress and fracture of snow slabs. [Union Géodésique et Géophysique Internationale. Association Internationale des Sciences Hydrologiques. Commission des Neiges et Glaces.] Symposium. Mécanique de la neige. Actes du colloque de Grindelwald, avril 1974, p. 208-21. (IAHS-AISH Publication No. I14.)

St. Lawrence, W. F., and Bradley, C. C. 1973. Ultrasonic emissions in snow. U.S. Dept. of Agriculture. Forest Service. General Technical Report RM-3, p. I-6.

\section{DISCUSSION}

R. L. BRown: I am somewhat confused at the final choice of $30 \mathrm{~Hz}$ for your system. Was this determined by slope dimensions and geometry, since $30 \mathrm{~Hz}$ could be a natural frequency of these slopes, or was it governed by the electronic characteristics of your equipment?

R. A. Sommerfeld: We arrived at $30 \mathrm{~Hz}$ (this last year) by performing a crude spectrum analysis which indicated an energy peak at about $30 \mathrm{~Hz}$.

Brown: Some of your noise counts could be due to wind noise, since $20-30 \mathrm{~Hz}$ signals transmit fairly well in snow. Therefore, transducer location relative to the snow surface or ground may be important. Where were your transducers located, and do you consider that wind noise may have produced any emissions?

Sommerfeld: The transducers were located in the body of the snow, approximately $0.7 \mathrm{~m}$ above the ground and $0.5^{-1.5} \mathrm{~m}$ below the snow surface. I pointed out in Figure I a period of several hours on 18-19 December when the wind was blowing strongly and the noise level was low.

P. FöHN: Only three avalanches appear to have been recorded so far. Was it possible to observe any different acoustic noise before "climax" avalanches and "direct-action" avalanches?

Sommerfeld: The first two avalanches were "direct-action" in that they occurred during storms. I am uncertain about the third. They all involved older snow layers. I would think that there would be little difference between the noise generated by these two avalanche types.

E. J. Langham: How are your geophones secured? Is it possible that some sound is being transmitted through the ground?

Sommerfeld: The geophones are attached to expanded metal grills and are floated within the snow. They probably do pick up some ground motions and I am sure that the chair-lift noise has a large ground component.

A. R. Dyunin: Do your geophones register the noise of cornice falls or that from all of the snow cover involved in an avalanche?

Sommerfeld: We pick up noise from several sources. Cornice falls, cornice falls combined with avalanches, slab avalanches, artificial avalanches and point avalanches have been shown by W. St. Lawrence to yield different identifiable signals. I think that the noises I have counted are transmitted from a region in the snow some tens of meters in diameter.

M. DE QUeRvain: Have avalanches been observed without any pre-warning by noise? Can the acoustic method of detecting low-stability snow be made operational for local avalanche warning? 
SOMmerfeld: We had one avalanche this last year which showed only a small increase in noise for a short preceding period $(3-4 \mathrm{~h})$. This avalanche was pulled out when the adjacent path was shot. We are going to try to operate a warning system this year which uses acoustic counts.

R. List: Could you specify how you extract your signal from the "noise" when you have no obvious correlations?

Sommerfeld: I amplify the signal from the recording tape, filter it through a band-pass filter set at the centre frequency ( $30 \mathrm{~Hz}$ for the data presented), and count the pulses on a counter or on a Hewlett Packard pulse-height analyzer in multi-channel scaling mode. The trigger level is set by the amount of amplification.

L. Davis: To assist in answering Dr List's question, I would suggest that by reducing the band width the total KTB noise is lowered. This means that Dr Sommerfeld is not extracting signals from the noise but reducing the total amount of noise. Due to the non-repetitive nature of the signals he is looking for, correlation techniques are not possible.

W. St. Lawrence: Since you use a variable trigger level, how do you account for days of high and low tectonic activity?

Sommerfeld: We do not account for varying tectonic activity. I rest my case on the correlation between noise counts and slope stability. It seems unlikely that tectonic activity correlates with avalanching but this is a basic question which needs to be resolved. 